\title{
Risk factors for mental, physical, and functional health in Gulf War veterans
}

\author{
Lynda A. King, PhD; ${ }^{1-3^{*}}$ Daniel W. King, PhD; ${ }^{1-3}$ Elisa E. Bolton, PhD; ${ }^{4}$ Jeffrey A. Knight, PhD; ${ }^{1-2}$ Dawne S. \\ Vogt, $\mathbf{P h D}^{\mathbf{1 - 2}}$ \\ ${ }^{1}$ National Center for Posttraumatic Stress Disorder; ${ }^{2}$ Boston University School of Medicine, Boston, MA; ${ }^{3}$ Department \\ of Psychology, Boston University, Boston, MA; ${ }^{4}$ Department of Veterans Affairs Boston Healthcare System, Boston, MA
}

\begin{abstract}
Risk factors associated with war-zone events and circumstances are implicated in the health and adjustment of military veterans. We assessed a national stratified sample of community-residing veterans of the Gulf War $(N=357)$ using scales from the Deployment Risk and Resilience Inventory, along with an array of mental (posttraumatic stress disorder, depression, and anxiety), physical (symptom and condition indicators especially pertinent to Gulf War illnesses), and functional (both mental and physical dimensions) health outcomes. We found that perceived threat or fear of bodily harm in the war zone and self-reported or perceived exposures to environmental hazards may play a critical role in all measured aspects of health. Moreover, a synergistic effect of these two risk factors was observed in the prediction of mental health and mental health functional status.
\end{abstract}

Key words: anxiety, Deployment Risk and Resilience Inventory, depression, environmental agents, functional health status, Gulf War illnesses, perceived threat, posttraumatic stress disorder, rehabilitation, risk factors, veteran health.

\section{INTRODUCTION}

A large body of professional and scientific literature has examined the vulnerability and protective factors related to the health and well-being of military veterans who have served in our wars [1-3]. Much of the research in this arena has concentrated on the influence of combat exposure as it relates to mental distress and longer-term mental disability, primarily symptoms of posttraumatic stress disorder (PTSD) [4], as well as comorbid mental health entities, such as symptoms of depression [5], symptoms of anxiety [6], substance abuse [7], and violent behavior [8]. Also, research into the effects of war-zone stressor exposure on veteran physical health [9] and general life adjustment and functioning [10] has been steadily increasing. A smaller subset of studies has disaggregated the global war zone experience to demonstrate how its multiple features may differentially affect health outcomes [11]. In addition to direct combat exposure, military personnel within a war zone typically confront episodes of extreme fear, exposure to the rather ghastly consequences of contemporary asymmetric warfare, lack of facilities and the usual comforts of daily life, and periods of boredom, among other stressors. Finally, one specific

\footnotetext{
Abbreviations: $\mathrm{CDC}=$ Centers for Disease Control and Prevention; $\mathrm{DOD}=$ Department of Defense; DRRI $=$ Deployment Risk and Resilience Inventory; IRB = institutional review board; NBC = nuclear, biological, or chemical; PTSD = posttraumatic stress disorder; SF-12 ${ }^{\circledR}=12$-Item Short Form Health Survey; SF-36 ${ }^{\circledR}=36$-Item Short Form Health Survey; VA = Department of Veterans Affairs.

*Address all correspondence to Lynda A. King, PhD; National Center for PTSD, 150 S. Huntington Ave, VA Boston (116B-5), Boston, MA 02130; 857-364-4938; fax: 857-3646520. Email: $\underline{\text { lking@bu.edu }}$
}

DOI: 10.1682/JRRD.2007.06.0081 
cohort of veterans, those deployed to the 1990-1991 Gulf War, has a unique stressor or risk factor: the belief that they could have been exposed to natural or man-made toxins that affect their postdeployment health.

Indeed, studies of the postwar health of Gulf War veterans have emphasized a search for environmental agents that might explain the physical and neurocognitive complaints of many veterans of that conflict (e.g., fatigue, musculoskeletal symptoms, and memory/concentration problems). In the years following the Gulf War, scientists, healthcare professionals, and veterans themselves believed that the incidence of distress and illness was likely a result of exposure to nuclear, biological, or chemical (NBC) agents. However, after 15 years of research, war-related psychosocial stressors are the one class of variables that has consistently survived scrutiny by various oversight committees that have examined the causes of the significant rates of distress and illness among Gulf War veterans. Reports issued by the Defense Science Board [12], National Institutes of Health [13], Institute of Medicine [14], Presidential Advisory Committee [15-16], the Persian Gulf Veterans Coordinating Board [17-18], and the Research Working Group of Military and Veterans Health Coordinating Board [19-20] all noted that exposure to stressful and traumatic events is a potential factor in Gulf War illnesses. Further, the important role of stress is highlighted in reviews of the scientific literature and recent articles on the health of Gulf War veterans [21-23].

Interestingly, several reports and research studies have advocated for the viability of an interaction between war-related psychosocial stressors and exposure to NBC agents in the prediction of health outcomes [15,24-27]. This expectation would suggest that in the presence of environmental toxins, the effect of psychosocial stressors on health outcomes is exacerbated. That is, for those individuals with higher exposure to toxic agents (the moderating variable), the association between psychosocial stressors and negative outcomes is stronger than for those exposed to lesser amounts of toxic agents. To our knowledge, this assertion of a synergistic effect has yet to be tested and represents the key issue addressed in this study.

We sought to document the potential influence of several war-related risk factors on a set of mental, physi$\mathrm{cal}$, and functional health outcomes using a national stratified sample of community-residing Gulf War veterans 10 years after the close of that conflict. The risk factors included three war-related psychosocial stressors, all assessed with the Deployment Risk and Resilience Inventory (DRRI) [28-29]: (1) perceived threat, a more subjective dimension that captures fear of harm or death; (2) combat experiences, a more objective report of actual warfare events; and (3) aftermath of battle, again a more objective account of exposure to the destructive consequences of war. A fourth risk factor, also drawn from the DRRI, was perceived exposure to NBC agents as reported by the veteran. This potential predictor of health and functioning was included because of its high degree of salience to the Gulf War veteran population and to accommodate the inquiry into potential synergistic effects, albeit with a self-report assessment of perceived NBC exposures. In selecting health outcomes, we chose a broad approach: (1) for mental health, the critical variable of PTSD symptoms and the often comorbid symptoms of depression and anxiety; (2) for physical health, symptom and condition indicators particularly germane to Gulf War illnesses; and (3) both physical and mental functional health status, in recognition that quality of life and health-symptom severity are not isomorphic.

Our general working hypothesis was that risk factors would be related to health outcomes in the expected direction. Beyond this general expectation, we hypothesized that the risk factor of perceived threat would be the most potent predictor- even more powerful than combat experiences-as has been demonstrated in prior studies of Vietnam veterans [11] and other Gulf War veteran samples [30]. Of the most importance, we anticipated interaction effects between war-related psychosocial risk factors and perceived exposure to environmental toxins reported by the veteran, in keeping with the synergistic hypothesis proposed in the literature.

\section{METHODS}

\section{Human Subject Considerations}

Human subject approval was obtained from the institutional review board (IRB) of the Department of Veterans Affairs (VA) Boston Healthcare System. In addition, the project upon which this study was based received approval from the Federal Office of Management and Budget pursuant to the requirements of the Paperwork Reduction Act of 1995. 


\section{Participants and Survey Procedures}

Using information supplied by the Department of Defense (DOD) Manpower Data Center and the VA, we selected a national sample of community-residing Gulf War veterans in accordance with a stratified random sampling plan. The sample was initially stratified on predeployment duty status and health registry status according to their representation in the larger population. Predeployment duty status refers to whether the individual was deployed to the Persian Gulf region from active duty or from National Guard/Reserve units. Registry status refers to whether or not an individual was enrolled in one of two health monitoring programs, either the Comprehensive Clinical Evaluation Program initiated by the DOD or the similar Gulf Registry Health Examination Program administered by the VA. Within these four groups, the sample was further stratified on sex; female veterans were oversampled to yield a sample distribution that was composed of approximately 75 percent men and 25 percent women.

A professional telephone survey organization with experience in national surveys of veteran populations conducted data collection. Prior to being contacted by telephone, veterans were informed by letter that they would be invited to participate in a telephone interview. A trained interviewer then contacted participants 2 weeks later. Each interview lasted approximately 45 minutes. The interview was accompanied by an invitation to contact a clinical psychologist (name and telephone number provided) if "any part of this conversation has been upsetting to you." In addition, the trained interviewers were provided with a detailed list ("Where to get help if people ask") of services related to VA facilities and general healthcare, marital and family counseling, spouse and child therapy, disability compensation, other benefits, and Gulf War illnesses. Only four participants contacted the clinical psychologist on call, whose records indicated that all four veterans called simply to say they had more information to provide to the study that they had not reported at the time of the interview. No distress calls were noted, and no incidents were reported to the IRB. The interview adhered to standard practices for the protection of human subjects (emphasis on the voluntary nature of participation, ability to stop the interview at any time, confidentiality, etc.).

The study was conducted in March and April of 2001, approximately 10 years after the Gulf War. A total of 1,572 telephone calls were initiated. Of these, 400
(25\%) were to numbers where contact could not be achieved (e.g., telephone disconnected, person of that name unknown to the call recipient, veteran deceased). For another 568 cases (36\%), one or more calls were completed to an answering machine or to another member of the family/household but not to the targeted veteran per se. Of the remaining 604 veterans (38\%) who were successfully contacted, 34 (6\%) did not qualify for the study (e.g., did not really serve in the war) and 36 (6\%) refused to participate or terminated the interview. Finally, 357 of the 604 contacts (59\%) were interviewed and provided data, while 177 of the 604 contacts (29\%) agreed to be interviewed but were not included because no more data were needed for completion of the stratification and sampling design quotas. Thus, locating veterans was a challenge (see comments in the "Clinical Implications and Limitations" section, p. 405) but, once veterans were located and personally recruited, their participation rates were quite good. See Table 1 for characteristics of the 357 participants who supplied data.

\section{Measures}

\section{DRRI War-Zone Stressor Measures}

Three war-zone stressor measures were taken from the DRRI [28-29], a collection of scales aimed at appraising factors that might render war veterans more or less vulnerable to postwar distress, adjustment difficulties, and ill health. The DRRI was developed to allow the characterization of war-related experiences from a multidimensional perspective. Recognizing that much of the trauma and PTSD literature for military personnel derived from the Vietnam War experience and focused overwhelmingly on combat exposure per se, the instrument authors sought to empirically support operationalizations of novel constructs that are also ecologically valid in terms of contemporary deployments and give a broader perspective on war-related events and circumstances. Using a rational classical test theory-oriented approach to test development, the authors placed particular emphasis on the soundness of the content of the core constructs, both content relevance and breadth, informed by a first-stage series of focus groups with members of the target population. Three additional data collections served to trim the item pool, provide early and confirmatory reliability estimates, and demonstrate nomological validity vis-à-vis expected group differences (e.g., men vs women, regular active duty vs National Guard/Reserve 
JRRD, Volume 45, Number 3, 2008

Table 1.

Participant characteristics.

\begin{tabular}{lc}
\multicolumn{1}{c}{ Variable } & Frequency (\%) \\
\hline Sex $(n=357)$ & $86(24)$ \\
Female & $271(76)$ \\
Male & \\
Age Group $(n=355)$ & $26(7)$ \\
$20-30$ & $124(35)$ \\
$31-40$ & $98(27)$ \\
$41-50$ & $91(26)$ \\
$51-60$ & $16(5)$ \\
$>60$ & \\
Ethnicity $(n=356)$ & $19(5)$ \\
Hispanic & $337(95)$ \\
Non-Hispanic & $1(0)$ \\
Race $(n=354)$ & $5(1)$ \\
Pacific Islander & $2(1)$ \\
American Indian/Alaskan Native & $55(15)$ \\
Asian & $289(82)$ \\
Black or African American & $2(1)$ \\
White & \\
Biracial & $279(22)$ \\
Military Branch $(n=357)$ & $19(5)$ \\
Marines & $277(77)$ \\
Army & $20(6)$ \\
Navy & $39(11)$ \\
Air Force & $238(1)$ \\
Coast Guard & \\
Predeployment Duty Status $(n=357)$ & \\
Active Duty & \\
National Guard/Reserves & \\
Registry Status $(n=357)$ & \\
Registry & \\
Nonregistry & \\
Sought Mental Health Care After War $(n)$ & \\
Yes & \\
No & \\
\hline \hline
\end{tabular}

personnel) and associations with health outcomes (e.g., neurocognitive functioning, PTSD symptoms, physical complaints).

The suite of 14 scales that comprise the full DRRI assesses multiple dimensions of the deployment experience: indicators of more objective as well as more subjective features of deployment, both higher magnitude and lower magnitude stressors, events and circumstances closely associated with the warrior mission, and interpersonal aspects that characterize the deployment experience. One or more DRRI scales may be used as standalone measures or the full inventory may be employed to evaluate predeployment, deployment, and postdeploy- ment dimensions that have implications for veteran health and adjustment. Further elaboration of the psychometric properties of the DRRI, including group means and indices of variability, internal consistency reliability, test-retest reliability, and validity coefficients are available elsewhere [28-29].

The first DRRI measure used in this study was the perceived threat scale, which is composed of 15 items that evaluate one's fear or sense of safety and well-being in the war zone, including judgments concerning potential threat to life or bodily integrity. This factor reflects emotional or cognitive appraisals of situations that may or may not accurately represent objective or factual reality. Sample items include "I was afraid that I would encounter a mine or booby trap," and "I felt I was in great danger of being killed or wounded." The response options are 1 = strongly disagree to $5=$ strongly agree. The total score is computed as the sum of the item ratings. The coefficient alpha for this scale is 0.89 .

A second war-zone stressor measure was the DRRI's combat experiences scale, which contains 20 items that document exposure to stereotypical warfare events and circumstances, such as firing a weapon, being fired on, witnessing injury and death, and going on special missions and patrols that involve such experiences. Sample items include "I went on combat patrols or missions," and "I fired my weapon at the enemy." Responses are coded dichotomously $(0=$ no, $1=$ yes $)$, with the total score computed as the sum of item responses.

The third measure of war-zone exposure was the DRRI's aftermath of battle scale. The 15 items in this measure reflect exposure to the consequences of combat, including observing or handling human remains, dealing with prisoners of war, and observing other consequences, such as devastated communities and homeless refugees. Sample items include "I took care of injured or dying people," and "I saw the bodies of dead civilians." This measure is also scored dichotomously ( $0=$ no, $1=$ yes $)$, with the total score calculated as the sum of item responses.

\section{DRRI Measure of Self-Reported NBC Exposures}

We also took a measure of self-reported NBC exposures from the DRRI. For this scale, participants were asked about exposure to 20 different types of agents that the respondents believed they had encountered while serving in the war zone. Sample items include "While I was deployed, I was exposed to pesticides in flea collars," 
and "While I was deployed, I was exposed to diesel or other petrochemical fuel on my skin.” Response options are $0=$ no exposure, 1 = don't know, and 2 = yes. A sum of affirmative responses was computed.

\section{Symptoms of PTSD and Comorbid Mental Health Problems}

PTSD symptoms were assessed with the PTSD Checklist-Military Version [31]. This scale contains 17 items that directly reference the cardinal symptoms of PTSD (intrusive thoughts and memories of the traumatic event, avoidance of reminders of the event, emotional withdrawal, and hyperarousal) as set forth in the Diagnostic and Statistical Manual of Mental Disorders-Fourth Edition [32]. Respondents rate on a 5-point scale (with anchors ranging from $1=$ not at all to $5=$ extremely) how much ". . . you have been bothered by that problem." In the present study, the time frame of "the past 3 months" was used. The coefficient alpha for this scale is 0.95, and it is highly correlated with other recognized measures of PTSD [33].

An adapted version of the 7-item Beck Depression Inventory-Primary Care was used to index depression symptoms [34]. This measure consists of seven statements extracted from the original Beck Depression Inventory [35] but with a variation in the response format. Sample items include "In the last 3 months, I have felt like a failure," and "In the last 3 months, I have had thoughts of killing myself.” Unlike the original Beck instrument, each item is rated on a 5-point scale, with anchors ranging from $1=$ strongly disagree to $5=$ strongly agree. Scores on the original Beck Depression Inventory have correlated well with clinicians' judgments of depression intensity [36]. The coefficient alpha for this brief form of the measure is 0.91 .

\section{Anxiety Symptoms}

Anxiety symptoms were measured with an abbreviated and adapted 7-item form [34] of the larger Beck Anxiety Inventory [37]. Sample items include "In the last 3 months, I have been unable to relax," and "In the past 3 months, I have had a fear of losing control.” Again, unlike the original Beck Anxiety Inventory, a 5-point response scale accompanies each item, with options $1=$ strongly disagree to $5=$ strongly agree. The full Beck Anxiety Inventory is highly correlated with other measures of anxiety [36]. The coefficient alpha for this 7-item version is 0.90 .

\section{Physical Health Outcomes}

Based on a review of the literature on health problems reported by Gulf War veterans [15-18,38-40], a list of 27 symptoms (e.g., skin disorders such as rashes, eczema, or psoriasis; recurrent headaches; wheezing, shortness of breath, or coughing) and 25 conditions (e.g., chronic fatigue syndrome, gastritis-gastroenteritis, fibromyalgia-fibrositis) was compiled. Participants used a yes-no format to indicate which physical symptoms they had experienced over the past 3 months (but not before or immediately after their deployment to the Persian Gulf region) and for which current (and not preexisting conditions) they had received a diagnosis by a physician or other health professional. A total symptom count was computed as the sum of endorsed symptoms. A total condition count was computed as the sum of all current diagnosed conditions.

In addition, a case definition of multisymptom Gulf War illnesses developed at the Centers for Disease Control and Prevention (CDC) was included as a third physical health outcome [38]. According to this case definition, an individual must have one or more chronic symptoms from at least two of three categories: (1) fatigue, (2) mood-cognition (feeling anxious, feeling moody, feeling depressed, difficulty sleeping, trouble finding words, difficulty remembering-concentrating), or (3) musculoskeletal (joint pain-stiffness, muscle pain). We used endorsement of the symptom "excessive tiredness" to assess the fatigue category. The mood-cognition category was indexed by the symptoms of "excessive moodiness," "excessive irritability," and "recurrent sleep disturbances" and by symptoms of problems with attentionconcentration-memory occurring at least once or twice a week. We used the symptoms "loss of muscle strength, muscle pain, or muscle exhaustion" and "joint pain or stiffness" to assess the musculoskeletal category. Each participant was classified as a case (or not) following the CDC guidelines.

\section{Functional Health Status}

The 12-Item Short Form Health Survey (SF-12 ${ }^{\circledR}$ ) [41-43] assessed physical functioning, role limitations due to physical problems, social functioning, bodily pain, general mental health, role limitations due to emotional problems, vitality, and general health perceptions. This measure is a shortened version of the full 36-Item Short Form Health Survey (SF-36 ${ }^{\circledR}$ ) [44]. We combined item scores to create two scale scores: one assessment of physical 
functional health status and one measure of mental functional health status. As with the full SF-36, scores on these physical and mental components are orthogonal. This abbreviated instrument has been found to reproduce at least 90 percent of the variance in the physical and mental subscales of the SF-36, which has well-established reliability and validity [44-45].

\section{Analyses}

To maximize the total number of items that could be administered to the full sample, we used a planned missingness design [46]. Six variations on the composition of the item set were systematically developed and randomly assigned and administered to subsets of study participants. To accommodate the resulting incomplete data, we implemented 10 data imputations [47]. The data then were analyzed using the Stata ${ }^{\circledR}$ software package (Stata Corp, LP; College Station, Texas) [48], with standard errors corrected for sample design weights and a 2 (predeployment duty status) $\times 2$ (registry status) $\times 2$ (sex) stratification structure. Design weights were calculated as the inverse of the probability of selection. Parameter estimates and their standard errors were combined across imputations according to Rubin's formulas [49]; the degrees of freedom were calculated with the updated formulas proposed by Barnard and Rubin [50].

Following the calculation of standard descriptive statistics and bivariate correlations between the DRRI pre- dictors and the mental, physical, and functional health outcomes, we relied on multiple regression as our primary analytic strategy. In a series of simultaneous multiple regression models, scores on the four DRRI scales (perceived threat, combat experiences, aftermath of battle, and self-reported NBC exposures) as well as the terms representing interactions of the first three of these DRRI factors with the NBC exposures variable (threat $\times$ $\mathrm{NBC}$, combat $\times$ NBC, and aftermath $\times$ NBC) were regressed on each of the eight outcomes. All independent variables were centered prior to the analyses. Also, to reduce the likelihood of Type 1 error, we used a familywise 0.01 level of significance with Bonferroni correction. Accordingly, independent variables in the multiple regression models were considered significant if the probability of a Type 1 error was $<0.0014$ (computed as 0.01 divided by 7 , the number of predictors in each model). With familywise Type 1 error rate limited to 0.01, experimentwise Type 1 error rate (over all eight analyses) was $<0.08$.

\section{RESULTS}

\section{Descriptive Statistics}

Table 2 reports the mean, standard deviation, and range for all study variables. Of particular interest is the

Table 2.

Descriptive statistics for all study variables.

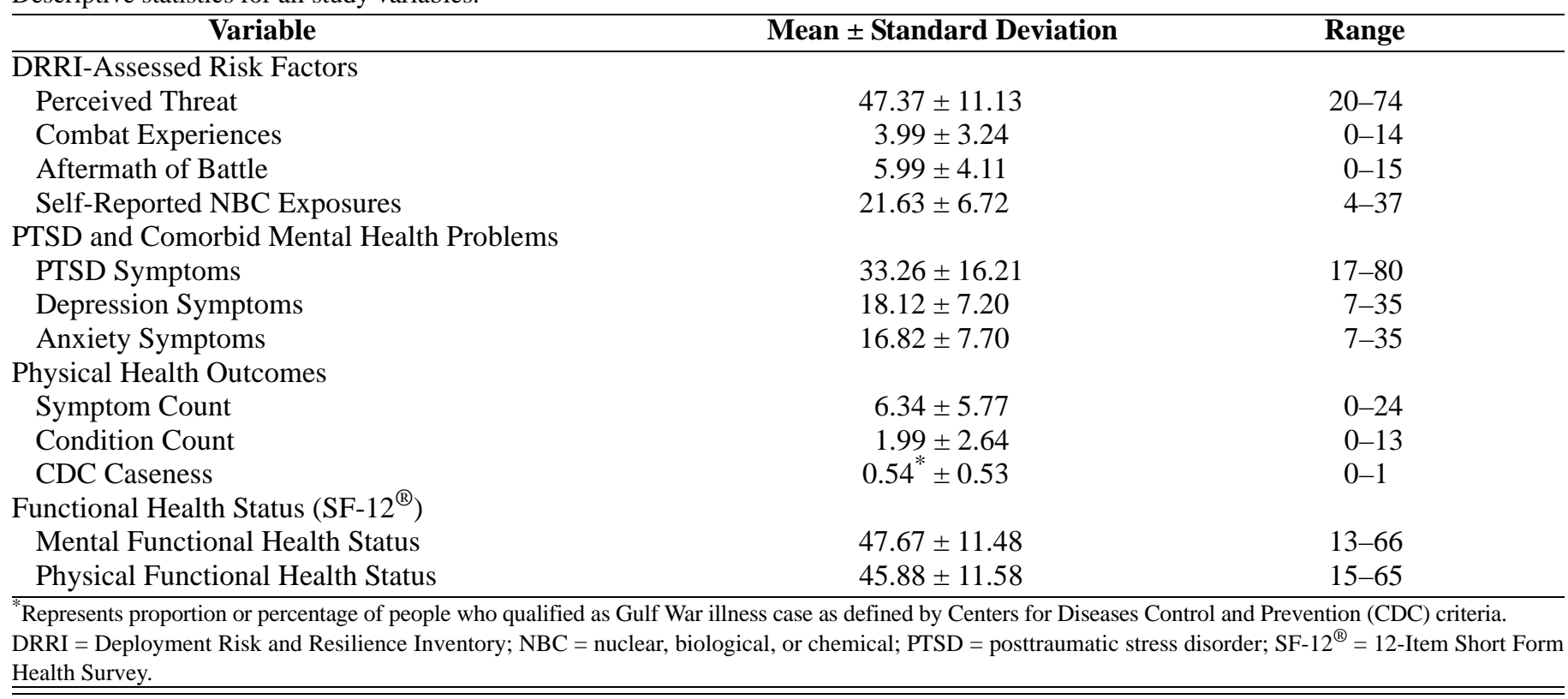


mean score of 33.26 on the PTSD Checklist-Military Version, which suggests that the average item response was just under 2 (indicating "a little bit” of difficulty or problem). Weathers and Ford reported an average of approximately 34 for Vietnam veterans without PTSD and an average of 64 for Vietnam veterans with PTSD; their optimal cutoff score for caseness was 50 [31]. Blanchard et al. reported an average score of about 46 for a sample of motor vehicle accident victims [33]; their optimal cutoff score for a diagnosis of PTSD was 44. Using the recommended Weathers and Ford cutoff score of 50 for the present group of veteran participants [31], we found that 16 percent of the population represented by this sample would screen positive for a PTSD diagnosis.

Also, some health outcomes have direct interpretation with regard to prevalence rates and comparisons of scores to normative standards. On average, respondents endorsed more than 6 of the 27 symptoms commonly associated with Gulf War illnesses and almost 2 of the 25 conditions for which a positive response required a physician's diagnosis. Although not reflected in Table 2 (because they are not primary outcomes but rather elements in the composite physical condition index included there), approximately 12 percent of the veterans reported physician-diagnosed chronic fatigue syndrome and 27 percent endorsed a physician-diagnosed musculoskeletal condition, either fibromyalgia-fibrositis or joint disease, both considered hallmark indices of Gulf War illnesses. With regard to our estimate of multisymptom illnesses using the CDC criteria, the mean value in Table 2 indicates that 54 percent of the respondents in this broad-based national sample could be considered cases. This proportion is slightly higher than the proportion of cases Fukuda and his CDC colleagues identified among their sample of Gulf War veterans drawn from Air Force National Guard and Air Force Reserve units (45\%) [38]. However, it is somewhat lower than the proportion of cases of multisymptom illnesses identified in another large study of Army Gulf War veterans (60\%) [27]. We should note that the estimate from the present study is within the range of these other two well-regarded investigations. Nonetheless, all of these prevalence estimates are quite high and call into question the discriminant validity of the Gulf War illnesses construct itself, if not also the sensitivity of the putative indicators as proposed by the CDC. Clearly, additional work to refine the syndrome is in order.

The SF-12 subscales indexing physical functional health status and mental functional health status averaged 45.88 and 47.67, respectively. These values fall just below the population mean of 50, as derived from the standardization and norm-based scoring system for this instrument ( $T$ scores: mean of 50, standard deviation of 10 ).

\section{Bivariate Associations Between DRRI Scales and Health Outcomes}

Table 3 presents bivariate correlations between the four DRRI risk factor scores and the set of mental, physical, and functional health outcomes. The large majority of these correlation coefficients attained statistical significance $(p<0.01)$. For ease of presentation, those correlations that equal or exceed what might be considered a

Table 3.

Bivariate correlations between risk factors and health outcomes. Correlations $\geq 0.20$ are underlined; correlations $\geq 0.35$ are displayed in bold. Some associations were reported previously as part of article on psychometric properties of Deployment Risk and Resilience Inventory (DRRI) [1].

\begin{tabular}{|c|c|c|c|c|c|c|c|c|}
\hline \multirow{2}{*}{$\begin{array}{l}\text { DRRI-Assessed } \\
\text { Risk Factor }\end{array}$} & \multicolumn{3}{|c|}{$\begin{array}{l}\text { PTSD \& Comorbid Mental } \\
\text { Health Problems }\end{array}$} & \multicolumn{3}{|c|}{ Physical Health Outcomes } & \multicolumn{2}{|c|}{$\begin{array}{c}\text { Functional Health } \\
\text { Status }\end{array}$} \\
\hline & $\begin{array}{c}\text { PTSD } \\
\text { Symptoms }\end{array}$ & $\begin{array}{l}\text { Depression } \\
\text { Symptoms }\end{array}$ & $\begin{array}{c}\text { Anxiety } \\
\text { Symptoms }\end{array}$ & $\begin{array}{l}\text { Symptom } \\
\text { Count }\end{array}$ & $\begin{array}{l}\text { Condition } \\
\text { Count }\end{array}$ & $\begin{array}{c}\text { CDC } \\
\text { Caseness }\end{array}$ & $\begin{array}{l}\text { SF-12 }{ }^{\circledR} \\
\text { Physical }\end{array}$ & $\begin{array}{l}\text { SF-12 }{ }^{\circledR} \\
\text { Mental }\end{array}$ \\
\hline Perceived Threat & $\underline{0.52}$ & 0.31 & $\underline{0.42}$ & $\underline{0.40}$ & $\underline{0.28}$ & $\underline{0.28}$ & -0.28 & -0.38 \\
\hline Combat Experiences & $\underline{0.32}$ & 0.16 & 0.18 & 0.18 & 0.10 & 0.11 & -0.21 & -0.18 \\
\hline
\end{tabular}

1. King LA, King DW, Vogt DS, Knight J, Samper RE. Deployment Risk and Resilience Inventory: A collection of measures for studying deployment-related experiences of military personnel and veterans. Mil Psych. 2006;18(2):89-120.

CDC = Centers for Disease Control and Prevention; NBC = nuclear, biological, or chemical; PTSD $=$ posttraumatic stress disorder; SF-12 ${ }^{\circledR}=12$-Item Short Form Health Survey. 
modest effect size of $r=0.20$ are underlined and those correlations that equal or exceed a moderate effect size of $r=0.35$ are displayed in bold type.

The most powerful associations were between perceived threat and health outcomes. In fact, perceived threat was associated at or above $r=0.20$ with all of the outcomes and at or above $r=0.35$ with four of the eight outcomes, in contrast to the correlations of the more objective event-based war-zone stressors (combat experiences and aftermath of battle) with health outcomes, where the associations were markedly weaker. Perhaps most noteworthy is the fairly strong correlation of $r=$ 0.52 between perceived threat and PTSD symptoms; for the more objective measures of combat experiences and aftermath of battle, the relationships with PTSD symptoms were notably weaker, $r=0.32$ and 0.28 , respectively.

The DRRI's self-reported NBC exposures variable was associated with each health outcome. In absolute value, correlations ranged from $r=0.27$ to $r=0.39$, with an average $r=0.31$. For this DRRI measure, the strongest bivariate correlations were with the total symptom count $(r=0.35)$ and PTSD symptoms $(r=0.39)$.

\section{Multiple Regression Analyses}

Table 4 presents the results of the multiple regression analyses for all health outcomes. The proportion of variance accounted for by the simultaneous model that involved all seven independent variables ranged from 11 percent in the prediction of CDC caseness (a pseudo- $R^{2}$ for this dichotomous outcome) to 37 percent in the prediction of PTSD symptoms. Across all eight equations, perceived threat and self-reported NBC exposures were consistent and significant main effects and in the expected directions: higher levels of perceived threat and more self-reported NBC exposures were associated with more negative health outcomes.

We found several significant interactions that involved perceived threat and self-reported NBC exposures: prediction of PTSD symptoms, anxiety symptoms, and mental functional health status. In addition, the model that predicted depression symptoms yielded a $t$ statistic of $3.12(p=0.0016)$ for the threat $\times$ NBC interaction effect that was just shy of reaching the specified significance boundary of 0.0014 . In all cases, the pattern of findings was the same. For individuals who thought that they were exposed to more NBC agents, the relationships between perceived threat in the Persian Gulf region and PTSD symptoms, anxiety symptoms, (possibly) depres- sion symptoms, and mental functional health status were relatively strong and in the expected direction. For individuals who self-reported low exposures to NBC agents, the associations between perceived threat and the outcomes were weaker. Such interaction effects did not exist for the physical health outcomes or for physical functional health status, and no other significant interactions were noted.

\section{DISCUSSION}

The findings of this study reveal that 10 years after the end of the Gulf War, the veterans of that conflict have health complaints that may be associated with their military service, results consistent with other major work $[21,23]$. As set forth in the general working hypothesis, the data reveal many significant associations between the four war-related DRRI-assessed risk factors and the collection of eight mental, physical, and functional health outcomes. With regard to the three war-related psychosocial stressors, findings were highly consistent with the hypothesis and with other existing literature [11,30,51] that perceived threat would be most salient. As noted previously, this more subjective risk factor tended to yield the strongest associations with outcomes and stands in contrast to the more objective psychosocial stressors of combat experiences and aftermath of battle. The second strongest predictor of health outcomes was self-reported or perceived NBC exposures, which surprisingly had slightly stronger associations with PTSD symptoms and symptoms of its comorbid mental health conditions than with the physical health indices that reflect Gulf War illnesses. Our findings are somewhat in contrast with the popular view that Gulf War veterans are suffering from physical health problems that can be accounted for by one or more specific NBC exposures [19-20,26,52]. The bivariate data suggest that many factors may account for veterans' current health and well-being rather than a single organized entity. The explanation for Gulf War veterans' physical health complaints is therefore likely quite complex.

Consistent with the bivariate findings, the main effects of combat experiences and aftermath of battle were negligible when they were entered simultaneously with perceived threat and self-reported NBC exposures in the multiple regressions for predicting health outcomes, even when PTSD symptoms served as the dependent 
Table 4.

Summary of multiple regression analyses.

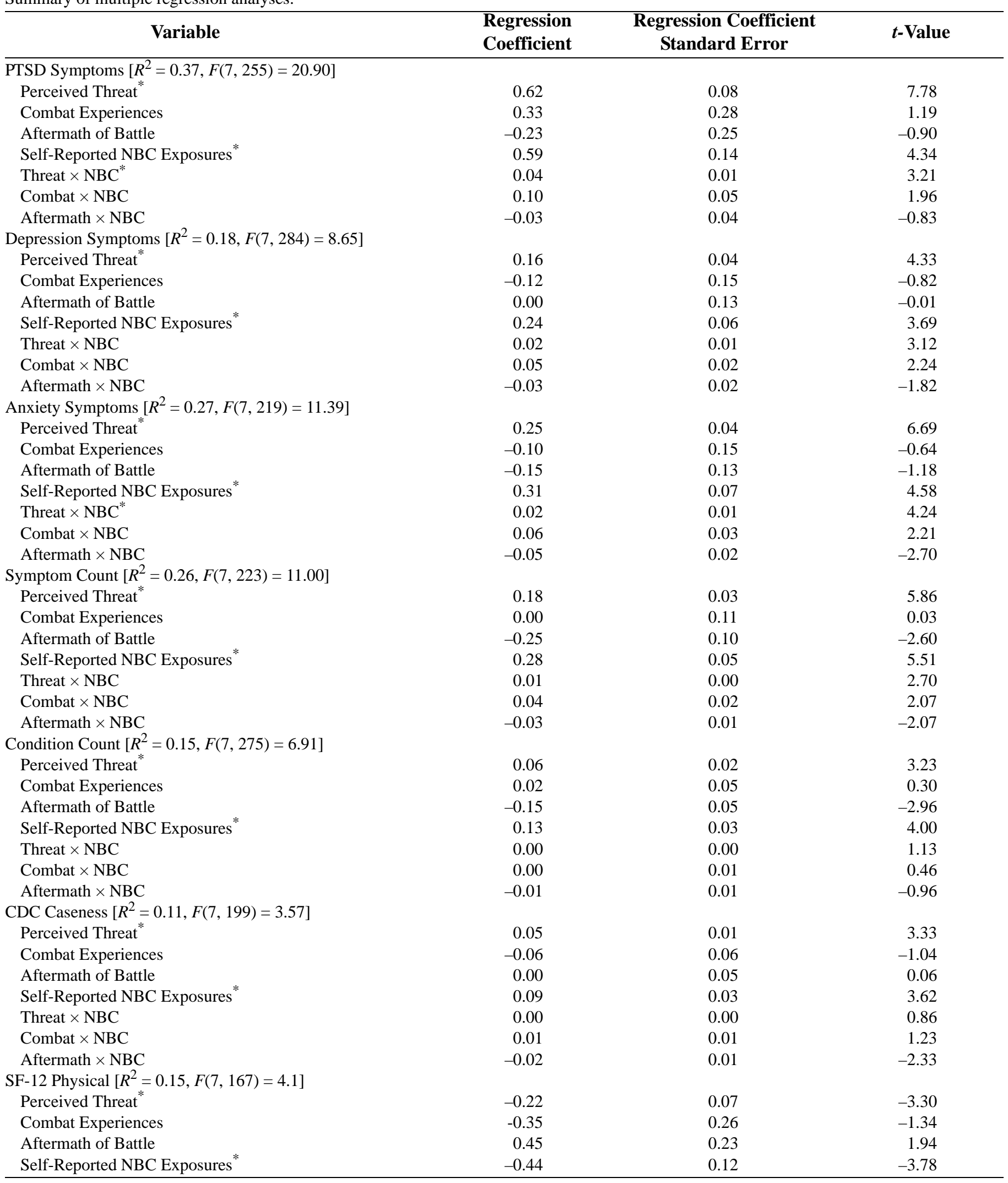


JRRD, Volume 45, Number 3, 2008

Table 4. (Continued)

Summary of multiple regression analyses.

\begin{tabular}{|c|c|c|c|}
\hline Variable & $\begin{array}{l}\text { Regression } \\
\text { Coefficient }\end{array}$ & $\begin{array}{l}\text { Regression Coefficient } \\
\text { Standard Error }\end{array}$ & t-Value \\
\hline Threat $\times$ NBC & -0.01 & 0.01 & -1.05 \\
\hline Combat $\times$ NBC & -0.07 & 0.04 & -1.74 \\
\hline \multicolumn{4}{|c|}{ SF-12 Mental $\left[R^{2}=0.22, F(7,213)=8.82\right]$} \\
\hline Perceived Threat ${ }^{*}$ & -0.35 & 0.06 & -6.09 \\
\hline Combat Experiences & -0.16 & 0.23 & -0.69 \\
\hline Self-Reported NBC Exposures* & -0.41 & 0.10 & -4.02 \\
\hline Threat $\times$ NBC $^{*}$ & -0.02 & 0.01 & -3.25 \\
\hline Combat $\times$ NBC & -0.08 & 0.04 & -2.24 \\
\hline Aftermath $\times$ NBC & 0.06 & 0.03 & 2.03 \\
\hline
\end{tabular}

${ }^{*}$ Significant at cutoff point established by Bonferroni correction, $p<0.0014$.

CDC = Centers for Disease Control and Prevention; NBC = nuclear, biological, or chemical; PTSD = posttraumatic stress disorder; SF-12 = 12-Item Short Form Health Survey.

variable. On the other hand, both perceived threat and self-reported NBC exposures were significant in all multiple regression analyses. These findings underscore the value of disentangling aspects of stressful and traumatic experiences (e.g., deployment to a war zone) to gain more useful information about what specific features of the global experience are most predictive of distress or ill health.

While the main effects of perceived threat and selfreported NBC exposures were consistently observed over all outcomes, their interpretation in the case of mental health and mental functional health status must be qualified by the interaction effects that were observed. That is, although each of these risk factors uniquely contributed to PTSD symptoms, anxiety symptoms, depression symptoms, and mental functional health status, the association between either one of these predictors and outcomes depended upon the level of the other predictor. Here, we found that with self-reported NBC exposures as the effect modifier, the greater the amount of environmental toxins to which veterans believed they were exposed, the stronger the relationship between their appraisal of fear or threat to life or bodily integrity and mental distress and emotional quality of life. For those who did not believe they were exposed to environmental toxins, the perceived threat-outcome association was weaker. Thus, support for synergistic effects was found, with perceived threat more predictive of poorer mental health and lower levels of mental functional health status for individuals who endorsed more exposures to environmental hazards.
However, further pinpointing the mechanism through which this threat $\times$ NBC interaction might play out requires disentangling actual NBC exposures from perceived NBC exposures, an undertaking that will likely never be accomplished with the population under study here. In point of fact, we purposefully have referred to the NBC variable as self-reported NBC exposures to emphasize that it, too, is a perceived variable and not necessarily an assertion of the actual state of affairs. It has been argued that unless or until more evidence is available on the presence of NBC toxic agents in the Gulf War, the report of exposures likely may be a surrogate for stress or anguish over the unknown long-term effects of the deployment [53]. To be sure, the search for verifiable markers of toxic exposures during the Gulf War was and is an ongoing process, presently with no documented, known, or unequivocally identified exogenous agents [12-20]. Therefore, one might interpret scores on the NBC exposures scale as manifestations of the respondent's subjective state of mind, wherein worry or fear of past possible toxic exposures further exacerbates the influence of accounts of threat or fear of harm that one faced in the war zone on subsequent symptoms of PTSD and comorbid mental health entities and on mental health-related quality of life. Alternatively, in the absence of actual illness, distress and somatic symptoms can lead to a search for meaning that culminates in an attribution to NBC exposures. With cross-sectional data, we can never fully explicate the direction of causality that underlies the observed associations. Regardless, we cannot rule out the possibility that specific health problems among 
small numbers of veterans from particular military units may be associated with discrete NBC exposures.

Overall, the risk factor models reflected in the multiple regression analyses were more effective in accounting for individual differences in mental health outcomes than individual differences in physical health outcomes. Perhaps the simplest explanation for this pattern is that the psychosocial and self-report predictors and their interactions would be expected to be more strongly associated with outcomes representing emotional states than with outcomes that intend to index physical status. As with other research on long-term consequences of warzone exposure [9], the effect on physical health appears to be more distal and is often mediated by cumulative effects of sustained emotional distress and associated risky health behaviors (e.g., alcohol use, smoking). At least with regard to the physical health outcomes, more precise prediction might be obtained by testing more complex models that include such variables.

\section{CLINICAL IMPLICATIONS AND LIMITATIONS}

Our results highlight the multifaceted relationship between the more objective (e.g., combat experiences) and more subjective (e.g., perceived threat) psychosocial stressors and their impact on the human body. As such, these data hold promise for increasing the efficacy of treatment for Gulf War and other veterans. Specifically, the association we found between subjectively assessed threat and health highlights the crucial role played by the cognitive interpretations of an event or events. Moreover, since perceived threat and self-reported exposure to NBC agents were shown to be related to distress-both as main effects and in interaction - then efforts for care and rehabilitation, physical and emotional, might benefit by inclusion of a component that targets appraisals and beliefs. Our findings do not necessarily suggest that treatment needs to refute or support the veracity of the threat or exposure, but they do highlight the possible important influence that thoughts have on emotions, or in this case, emotional distress. In addition, as interpretations of events have been shown to be amenable to intervention, cognitive-behavioral therapies might be able to improve veteran health and quality of life by reframing the threat or associated fear-provoking cognitions and placing them in a reasonable context that is more approachable and controllable and less overwhelming and intrusive in day-today behaviors and thoughts. Although few studies have focused on cognitive behavior applications to Gulf War veterans' physical health (see Donta and colleagues [54] for an exception), such interventions have been demonstrated to be effective adjunct therapies in other related populations, including those with fibromyalgia [55], chronic pain [56], headache, chronic fatigue syndrome, and tinnitus [57], and may prove useful in future treatment programs for veterans with physical health complaints that reflect potential Gulf War illnesses.

We duly recognize the limitations related to the difficulty in locating veterans 10 years after their service and that those veterans who agreed to be interviewed, even at a very high rate, may be systematically different from those who could not be located. We should also note that all data in this study were self-reported and, as such, are subject to the cautions that self-report data engender. In addition, the cross-sectional design, as previously pointed out, necessarily introduces ambiguity about the direction of causal influence. Indeed, a common factor, interpreted in terms of general distress, neuroticism, or some similar construct may influence responses to measures in this study, especially those that may be broadly characterized as indicators of internal states (either predictors or outcomes). On the other hand, an advantage of this study is that it used a national survey of communityresiding veterans. Furthermore, as noted earlier, we demonstrated the benefits of assessing multiple facets of the war-zone experience to gain a more precise parsing of differential effects on health and how they might operate in a synergistic fashion.

\section{ACKNOWLEDGMENTS}

This material was based on work supported by a collaborative program sponsored by the DOD and VA (under the auspices of the U.S. Army Medical Research and Materiel Command, Ft. Detrick, Maryland; DOD PG-087). Additional support was provided by the Massachusetts Veterans Epidemiology Research and Information Service, VA Boston Healthcare System.

The authors have declared that no competing interests exist.

\section{REFERENCES}

1. Kaylor JA, King DW, King LA. Psychological effects of military service in Vietnam: A meta-analysis. Psychol Bull. 1987;102(2):257-71. [PMID: 3659223] 
2. King DW, King LA. Validity issues in research on Vietnam veteran adjustment. Psychol Bull. 1991;109(1):107-24. [PMID: 2006223]

3. King DW, Vogt DS, King LA. Risk and resilience factors in the etiology of chronic posttraumatic stress disorder. In: Litz BT, editor. Early interventions for trauma and traumatic loss. New York (NY): Guilford Press; 2004. p. 34-64.

4. Fontana A, Rosenheck R. A causal model of the etiology of war-related PTSD. J Trauma Stress. 1993;6(4):475-500.

5. Sharkansky EJ, King DW, King LA, Wolfe J, Erickson DJ, Stokes LR. Coping with Gulf War combat stress: Mediating and moderating effects. J Abnorm Psychol. 2000;109(2): 188-97. [PMID: 10895556]

6. Vogt DS, Pless AP, King LA, King DW. Deployment stressors, gender, and mental health outcomes among Gulf War I veterans. J Trauma Stress. 2005;18(3):272-84. [PMID: 16281224]

7. Bremner JD, Southwick SM, Darnell A, Charney DS. Chronic PTSD in Vietnam combat veterans: Course of illness and substance abuse. Am J Psychiatry. 1996;153(3): 369-75. [PMID: 8610824]

8. Taft CT, Pless AP, Stalans LJ, Koenen KC, King LA, King DW. Risk factors for partner violence among a national sample of combat veterans. J Consult Clin Psychol. 2005; 73(1):151-59. [PMID: 15709842]

9. Taft CT, Stern AS, King LA, King DW. Modeling physical health and functional health status: The role of combat exposure, posttraumatic stress disorder, and personal resource attributes. J Trauma Stress. 1999;12(1):3-23. [PMID: 10027139]

10. Vogt DS, King DW, King LA, Savarese VW, Suvak MK. War-zone exposure and long-term general life adjustment among Vietnam veterans: Findings from two perspectives. J Appl Soc Psychol. 2004;34(9);1797-1824.

11. King DW, King LA, Gudanowski DM, Vreven DL. Alternative representations of war zone stressors: Relationships to posttraumatic stress disorder in male and female Vietnam veterans. J Abnorm Psychol. 1995;104(1):184-95. [PMID: 7897042]

12. Defense Science Board. Report of the Defense Science Board Task Force on Persian Gulf War Health Effects. Office of the Under Secretary of Defense for Acquisition and Technology. Washington (DC): 1994. p. 1-102.

13. The Persian Gulf experience and health. NIH Technology Assessment Workshop Panel. JAMA. 1994;272(5):391-96. [PMID: 8028172]

14. Institute of Medicine. Health consequences of service during the Persian Gulf War: Recommendations for research and information systems. Washington (DC): National Academy Press; 1996.

15. Lashof JC. Presidential Advisory Committee on Gulf War veterans' illnesses: Final report. Washington (DC): Government Printing Office; 1996.
16. Lashof JC. Presidential Advisory Committee on Gulf War veterans' illnesses: Special report. Washington (DC): Government Printing Office; 1997.

17. Persian Gulf Veterans Coordinating Board. A working plan for research on Persian Gulf veteran's illnesses. Washington (DC): Department of Veterans Affairs; 1997.

18. Persian Gulf Veterans Coordinating Board. Annual report to Congress: Federally sponsored research on Persian Gulf veterans' illnesses. Washington (DC): Department of Veterans Affairs; 1997.

19. Research Working Group of Military and Veterans Health Coordinating Board. Annual report to Congress: Federally sponsored research on Gulf War veterans' illnesses. Washington (DC): Department of Veterans Affairs; 2001.

20. Research Working Group of Military and Veterans Health Coordinating Board. Annual report to Congress: Federally sponsored research on Gulf War veterans' illnesses. Washington (DC): Department of Veterans Affairs; 2002.

21. Blanchard MS, Eisen SA, Alpern R, Karlinsky J, Toomey R, Reda DJ, Murphy FM, Jackson LW, Kang HK. Chronic multisymptom illness complex in Gulf War I veterans 10 years later. Am J Epidemiol. 2006;163(1):66-75. [PMID: 16293719]

22. Marshall GN, Davis LM, Sherbourne CD. A review of the scientific literature as it pertains to Gulf War illnesses. Vol. 4. Stress. Santa Monica (CA): RAND; 1999.

23. Toomey R, Kang HK, Karlinsky J, Baker DG, Vasterling JJ, Alpern R, Reda DJ, Henderson WG, Murphy FM, Eisen SA. Mental health of U.S. Gulf War veterans 10 years after the war. Br J Psychiatry. 2007;190:385-93. [PMID: 17470952]

24. Hotopf M, David A, Hull L, Ismail K, Unwin C, Wessely $\mathrm{S}$. Role of vaccinations as risk factors for ill health in veterans of the Gulf war: Cross sectional study. BMJ. 2000; 320(7246):1363-67. [PMID: 10818024]

25. Research Working Group of Military and Veterans Health Coordinating Board. Annual Report to Congress: Federally sponsored research on Gulf War veterans' illnesses. Washington (DC): Department of Veterans Affairs; 2000.

26. Sartin JS. Gulf War illnesses: Causes and controversies. Mayo Clin Proc. 2000;75(8):811-19. [PMID: 10943235]

27. Wolfe J, Proctor SP, Erickson DJ, Hu H. Risk factors for multisymptom illness in U.S. Army veterans of the Gulf War. J Occup Environ Med. 2002;44(3):271-81. [PMID: 11911029]

28. King DW, King LA, Vogt DS. Manual for the Deployment Risk and Resilience Inventory (DRRI): A collection of measures for studying deployment-related experiences in military veterans. Boston (MA): National Center for PTSD; 2003.

29. King LA, King DW, Vogt DS, Knight J, Samper RE. Deployment Risk and Resilience Inventory: A collection of measures for studying deployment-related experiences of 
military personnel and veterans. Mil Psych. 2006;18(2): 89-120.

30. Vogt DS, Tanner LR. Risk and resilience factors for posttraumatic stress symptomatology in Gulf War I veterans. J Trauma Stress. 2007;20(1):27-38. [PMID: 17345645]

31. Weathers F, Ford J. Psychometric review of PTSD Checklist (PCL-C, PCL-S, PCL-M, PCL-PR). In: Stamm BH, editor. Measurement of stress, trauma, and adaptation. Lutherville (MD): Sidran Press; 1996. p. 250-51.

32. American Psychiatric Association. Diagnostic and statistical manual of mental disorders. 4th ed. Washington (DC): American Psychiatric Association; 1994.

33. Blanchard EB, Jones-Alexander J, Buckley TC, Forneris CA. Psychometric properties of the PTSD Checklist (PCL). Behav Res Ther. 1996;34(8):669-73. [PMID: 8870294]

34. Beck AT, Steer RA, Ball R, Ciervo CA, Kabat M. Use of the Beck Anxiety and Depression Inventories for primary care with medical outpatients. Assessment. 1997;4(3):211-19.

35. Beck AT, Ward CH, Mendelson M, Mock J, Erbaugh J. An inventory for measuring depression. Arch Gen Psychiatry. 1961;4:561-71. [PMID: 13688369]

36. Beck AT, Steer RA, Garbin MG. Psychometric properties of the Beck Depression Inventory: Twenty-five years later. Clin Psychol Rev. 1988;8(1):77-100.

37. Beck AT, Epstein N, Brown G, Steer RA. An inventory for measuring clinical anxiety: Psychometric properties. J Consult Clin Psychol. 1988;56(6):893-97. [PMID: 3204199]

38. Fukuda K, Nisenbaum R, Stewart G, Thompson WW, Robin L, Washko RM, Noah DL, Barrett DH, Randall B, Herwaldt BL, Mawle AC, Reeves WC. Chronic multisymptom illness affecting Air Force veterans of the Gulf War. JAMA. 1998;280(11):981-88. [PMID: 9749480]

39. Haley RW. Is Gulf War syndrome due to stress? The evidence reexamined. Am J Epidemiol. 1997;146(9):695-703. [PMID: 9366616]

40. Self-reported illness and health status among Gulf War veterans. A population-based study. The Iowa Persian Gulf Study Group. JAMA. 1997;277(3):238-45.

[PMID: 9005274]

41. Ware JE, Kosinski M, Keller SD. SF-12: How to score the SF-12 physical and mental health summary scales. 2nd ed. Boston (MA): The Health Institute, New England Medical Center; 1995.

42. Ware JE, Kosinski M, Keller SD. SF-12: An even shorter health survey. Med Outcomes Trust Bull. 1996;4(1):2.

43. Ware J Jr, Kosinski M, Keller SD. A 12-Item Short-Form Health Survey. Construction of scales and preliminary tests of reliability and validity. Med Care. 1996;34(3):220-33. [PMID: 8628042]

44. Ware JE Jr, Sherbourne CD. The MOS 36-item short-form health survey (SF-36). I. Conceptual framework and item selection. Med Care. 1992;30(6):473-83.

[PMID: 1593914]
45. Ware JE, Snow KK, Kosinski M, Gandek B. SF-36 health survey: Manual and interpretation guide. Boston (MA): The Health Institute, New England Medical Center; 1993.

46. Graham JW, Hofer SM, MacKinnon DP. Maximizing the usefulness of data obtained with planned missing value patterns: An application of maximum likelihood procedures. Multivariate Behav Res. 1996;31(2):197-218.

47. Schafer JL. Analysis of incomplete multivariate data. London (England): Chapman and Hall; 1997.

48. Stata Corporation. Stata reference manual: Release 6. College Station (TX): Stata Corporation; 1999.

49. Rubin DB. Multiple imputations for no response in surveys. New York (NY): Wiley; 1987.

50. Barnard J, Rubin DB. Miscellanea. Small-sample degrees of freedom with multiple imputation. Biometrika. 1999; 86(4):948-55.

51. Nisenbaum R, Barrett DH, Reyes M, Reeves WC. Deployment stressors and a chronic multisymptom illness among Gulf War veterans. J Nerv Ment Dis. 2000;188(5):259-66. [PMID: 10830562]

52. Bieliauskas LA, Turner RS. What Persian Gulf War syndrome? Clin Neuropsychol. 2000;14(3):341-43.

[PMID: 11262709]

53. Spencer PS, McCauley LA, Lapidus JA, Lasarev M, Joos SK, Storzbach D. Self-reported exposures and their association with unexplained illness in a population-based case-control study of Gulf War veterans. J Occup Environ Med. 2001;43(12):1041-56. [PMID: 11765675]

54. Donta ST, Clauw DJ, Engel CC Jr, Guarino P, Peduzzi P, Williams DA, Skinner JS, Barkhuizen A, Taylor T, Kazis LE, Sogg S, Hunt SC, Dougherty CM, Richardson RD, Kunkel C, Rodriguez W, Alicea E, Chiliade P, Ryan M, Gray GC, Lutwick L, Norwood D, Smith S, Everson M, Blackburn W, Martin W, Griffiss JM, Cooper R, Renner E, Schmitt J, McMurtry C, Thakore M, Mori D, Kerns R, Park M, Pullman-Mooar S, Bernstein J, Hershberger P, Salisbury DC, Fuessner JR; VA Cooperative Study \#470 Study Group. Cognitive behavioral therapy and aerobic exercise for Gulf War veterans' illnesses: A randomized controlled trial. JAMA. 2003;289(11):1396-1404. [PMID: 12636462]

55. Thieme K, Flor H, Turk DC. Psychological pain treatment in fibromyalgia syndrome: Efficacy of operant behavioural and cognitive behavioural treatments. Arthritis Res Ther. 2006; 8(4):R121. [PMID: 16859516]

56. Kerns RD, Thorn BE, Dixon KE. Psychological treatments for persistent pain: An introduction. J Clin Psychol. 2006; 62(11):1327-31. [PMID: 16937343]

57. Jackson JL, O’Malley PG, Kroenke K. Antidepressants and cognitive-behavioral therapy for symptom syndromes. CNS Spectr. 2006;11(3):212-22. [PMID: 16575378]

Submitted for publication June 4, 2007. Accepted in revised form November 5, 2007. 